\title{
Comorbidity in ADHD: A Neuropsychological Perspective
}

\author{
Julio César Flores Lázaro and María Alejandra Salgado Soruco \\ ${ }^{1}$ SAP-Institutos Nacionales de Salud, Secretaría de Salud, \\ ${ }^{2}$ BUAP-Maestría en Neuropsicología, \\ México
}

\section{Introduction}

ADHD is commonly defined as a condition that affects attention, learning and behavior (American Psychiatric Association, 2001). Despite that over twenty years of scientific research has defined ADHD as a neurodevelopmental disorder, with the higher hereditability among psychiatric disorders; clinical-empirical taxonomy (DSM-IV) still prevail (McGough \& McCracken, 2006).

From an empirical point of view, other difficulties and also disorders that accompany this condition are considered "comorbid" (meaning: secondary). However several studies have found that quality of life in adolescents and adults with ADHD-child-diagnostic is not only related with attention deficits-severity, but also-mainly to comorbidity (Klassen, Miller \& Fine, 2004). Yang et al. (2007) studied a sample of 1000 children and adolescents with ADHD, finding that comorbidity symptoms increases in relations to age, reaching the highest impact on behavior by the end of adolescence. Other studies are in agreement that in transition to adulthood comorbidity tends to: a) increase in intensity, and/or b) to appear for the first time (Kessler et al., 2006).

Particularly conduct and negativistic disorders are highly related with other types of comorbidity (Rhee, Willcutt, Hartman, Pennington \& Defries, 2007); some studies have found that comorbidity-type could be more important than attention-deficits-severity to produce and explain clinical behaviors: in general literature indicates that when ADHD and conduct disorder are clearly present and combined, the psychological impact is far more important than the effects produced separately by each disorder (Waschbusch, 2002); this impact is not found in the same magnitude for anxiety, depression or bipolar disorder (Pliszka, 2006). Flory et al. (2003) studied 481 adults with childhood-ADHD diagnosis, finding that subjects with higher characteristics for conduct disorder presented higher levels of drug consumption; in this same perspective Donohew et al. (1999) reported a relationship between the sensation seeking behavior profile and drug consumptions in adolescents (alcohol and marihuana). Harty et al. (2009) studied 87 children with ADHD, selecting from this sample subjects with oppositional defiant disorder diagnosis, and conduct disorder, applying diverse behavioral scales to set an initial evaluation during childhood (aggression, anger, and hostility), and a second evaluation teen years later. Finding that the ADHD- 
conduct disorder group presented higher levels of physical aggression in adolescence; both comorbid groups presented significant increment of anger (compared with adolescents with ADHD-only). Authors propose that emotional dysregulation could be an important component for ADHD during transition from childhood to adolescence.

Specific results on ADHD from the national comorbidity survey replication (Kessler et al., 2006) show a very important negative relation between years of school and symptoms prevalence: adults with ADHD profile presents fewer years of education, even adults with childhood onset without current full-symptoms presents a tendency to have mid to low education level (compared with the general population).

This report outlines that a diverse number of studies that have documented high societal costs for anxiety, mood and substance use disorders, have not included the role of comorbid ADHD. Indicating that only $10 \%$ of respondents diagnosed with ADHD reported having received treatment for adult $\mathrm{ADHD}$, this percentage is significantly lower than the reported rates for anxiety, mood, or substance use disorders. Revealing that many people with adultADHD are in treatment for other mental or substance use disorders but not for ADHD (Kessler et al., 2006).

ADHD symptoms overlap and are frequently prevalent among patients with others psychiatric disorder (mood, anxiety, substance use, and impulse control disorders). Metanalysis have shown that DSM-IV criteria for adult-ADHD has unclear validity, provoking underdiagnosis (Simon et al. 2009). This clinical under-recognition may negatively influence treatment effectiveness and outcome success (Barkley \& Brown, 2008).

McGough et al. (2009) interviewed 435 parents in 230 families with at least one affected children (present or past) with ADHD, using different rating scales based on DMSM-IV. Parents affected with ADHD (past or present affection) presented lower educational and occupational achievement, higher rates of lifetime comorbidity for depression, anxiety, disruptive behaviors, and substance use disorder. Higher risk for disruptive disorder was predicted only by male sex and ADHD; substance use disorder was mainly predicted by disruptive behavior disorders, male sex, and lower socioeconomic status.

Sex differences in comorbidity have also been found: in women drug consumption is mainly related to depression and anxiety (McGough et al., 2005). Ruhl et al. (2009) studied 2064 young-women (aged 18-25) with a structured interview according to DMS-IV criteria. Finding a $1.5 \%$ lifetime prevalence for ADHD, with 14\% still suffering from ADHD since Childhood. Lifetime prevalence for conduct, somatoform, or posttraumatic stress disorder was significant higher in ADHD-women. Females with past or current ADHD-diagnosis were almost twice vulnerable to suffer from depressive or phobic disorder (than women from the general population). Authors also highlights that even when ADHD-diagnostic criteria is no longer fulfilled in adulthood, women with ADHD since childhood presents and increased prevalence for psychiatric comorbidity.

\section{Is comorbidity a psychological science?}

Drake and Wallach's (2007) article title is a perfect frame to develop this issue, like Stefanatos and Baron (2007) they propose scientific frames for conceptualizing and studying ADHD-comorbidity, instead of "clinical-empirical" criteria. 
Barkley (2009) and other scientists (i.e. Diamond, 2005) have demonstrated conceptual limitations in DSM-IV conceptualization for ADHD: according to Barkley diagnostic sensitivity to impulsivity symptoms is underrepresented in DSM-IV; pointing out that from a scientific-cognitive perspective, behavioral and cognitive control does not depend of attentional but on executive functions (these functions are mainly dependent on prefrontal cortex development -Diamond, 2001; van Leijenhorst et al., 2010-). They also highlights that others symptoms-behaviors-characteristics that could differentiate impulsivity like another possible category in ADHD are not appropriately represented in DSM-IV criteria.

Manassis et al. (2007) have found that children with anxiety disorders present an enhanced perception for negative emotions, specifically an incremented response in attention and memory processing to threatening stimuli; whereas ADHD-anxiety children didn't exhibited this profile. Authors consider that for each group anxiety may present different psychophysiological causes and characteristics.

Studies that compared children with ADHD-only vs children with ADHD-oppositional defiant disorder, reports attenuated electrophysiological responses (less P300 activation to cues) during attentional tasks (Continuous Performance Task: CPT) specifically for children with ADHD-only; indicating difficulties with anticipation and response preparation. This electrophysiological pattern is absent in ADHD-oppositional defiant disorder, indicating that comorbidity should not be viewed as a simple clinical-addition (Luman et al., 2009).

A consistent relationship between right hemisphere activation and a perceptual bias for negative emotions (fear, anxiety and sadness) has been frequently documented: more rightfrontal activity is found in shy-evitative children, and in subjects with depression and anxiety; in contrast more lef-frontal activity is found in sociable and low-social-fear children (McManis, Kagan, Snidman \& Woodwrad, 2000). By studying children with ADHD and their parents (affected and not affected), with electrophysiological recording during an attentional task (CPT), Hale et al. (2010) found that affected subjects (children and parents) presented an increased rightward asymmetry across frontal and central regions. An interesting relationship has been found: increased ADHD-familial loading correlated with increased rightward frontal asymmetry, instead increased rightward parietal asymmetry was correlated with reduced ADHD-family loading. Overall, this psychophysiological profile could predispose subjects with ADHD to be perceptually-biased to negativeemotional processing.

Schwartz et al. (2010) measured the orbito-frontal cortex density in normal subjects (18 years old) previously characterized in infancy as low-reactive or high-reactive subjects, finding that participants with low-reactive infant temperament presents greater thickness in the left orbito-frontal cortex, while subjects with high-reactive infant temperament present greater thickness in the right orbito-frontal cortex.

In literature it's been described that children with conduct disorder present mainly motivational problems, whereas children with ADHD present mainly attention deficits; Rubia et al. (2009) studied (by functional magnetic resonance imaging) 14 children with conduct disorder, and 18 children with ADHD; using a reward continuous performance task, and a sustained attention task. Results show brain activation differences between groups: conduct disorder subjects presented underactivation in paralimbic regions whereas ADHD subjects presented underactivation in diverse cerebral areas including prefrontal 
cortex. During the reward condition, conduct disorder subjects presented underactivation in right orbito-frontal cortex, while ADHD presented underactivation in posterior cingulated and precuneus; indicating neurocognitives differences among different clinical profiles.

Luman et al. (2009) found some neuropsychological differences among ADHD-children vs. ADHD-oppositional defiant disorder (ODD): children with ADHD-only presented difficulties in inhibition, timing estimation and reinforcement sensitivity, whereas children with ADHD-ODD presented an increased variability in timing estimation. Authors concluded that ADHD-ODD do not represent a more severe form of ADHD, instead a different one.

These studies indicate that neurocognitive/neuropsychological profiles are more specific and clinically illustrative for understanding comorbidity. Diverse authors has outlined that comorbidity is not only accompanying the disorder, and do not represent a clinical ambiguous variant for a given disorder. Instead the disorder itself and other -apparently no primarily related-clinical characteristics could depend on common cognitive, psychological and/or neuropsychological mechanisms.

Due that ADHD-comorbidity physiopathology is highly heterogeneous, it's been proposed that -scientific- models of comorbidity should be proposed. (Drake \& Wallach, 2007; Stefanatos \& Baron; 2007, Taurines et al. 2010). And although a neuropsychological approximation to understand the basic mechanisms of "psychological" disorders is continuously increasing, the neuropsychological profile for each disorder hasn't yet acquired a central role in diagnosis and treatment (Beblo, Sinnamon \& Baune, 2011: Neuropsychology Review). However with this approximation an optimal comprehension for this "attentional" disorder could be achieved (Diamond \& Anso, 2008).

\section{A neuropsychological perspective in ADHD}

From a neuropsychological perspective comorbidity is considered part of the same brain and cognitive mechanisms that produces attentional and or behavioral difficulties (Barkley, 2009; Diamond, 2005): children with attentional-variant presents a different (opposite) pattern of cognitive and behavioral profile than children with the hyperactive-variant. Inattentive profile includes social isolation, behavioral passivity, and cognitive slowness; in contrast hyperactive profile includes aggressive behavior, emotional instability, cognitive impulsivity and social disruptiveness (Flores Lázaro, 2009; Maedgen \& Carlson, 2000).

Attentional mechanisms do not represent a general-valid construct to explain: rejection to follow rules and to perform organized-structured activities, immediate seeking for gratification, low motivational drive, emotional lability, etc (Diamond, 2005). Instead of comorbidity summation, basics and common neuropsychological mechanism are proposed in order to explain from wider perspective attentional, behavioral and psychological profiles (Barkley, 1997, 2009; Stefanatos \& Baron, 2007).

The principal neuropsychological characteristics seen in ADHD could be explained by deficits in executive function, these functions depends on different brain circuits mainly located in prefrontal cortex (Barkley, 2010); for example children with combined-ADHD present more deficits in strategic memory -an executive function- than children with inattentive-ADHD type (Castel, Humpreys \& Moore, 2011). Executive functions permits 
complex cognitive and behavioral control, and are critical for success in school and daily life (Diamond, 2011).

\section{Attentional sub-type as an ADHD-cortical form}

Metanalysis of 19 developmental-functional neuroimaging studies in normal subjects has found that: fronto-parietal networks-interaction allows conscious-cognitive control of attentional processes. During brain development, functional integration between these and others networks is constructed; this phenomena also permits functional integration among several executive functions like inhibitory control, set switching and working memory (Fair et al., 2007). Inattentive predominant profile in children with ADHD includes difficulties in working memory, volume and processing speed, primary learning difficulties, and social isolation; the absence of behavioral difficulties as dominant profile, implicates neo-cortical mechanism that explains predominant cognitive consequences (Diamond, 2005).

Attentional control (focusing, stability, and alternation) and attentional processing (volume, processing speed) for cognitive academic and working environmental demands, depends mainly on cortical control -top-down regulation-; during child development, delay and inadequate integration between fronto-parietal networks leads to difficulties in attentional control and other executive functions (Fair et al., 2007). Stimulants like atomoxetin enhances prefrontal cortex functioning in ADHD-subjects -trough adrenergic and dopamine receptors- (Gamo et al., 2010); with positive psychophysiological results.

\section{Hyperactive sub-type as a ADHD-fronto-striatal form}

Hyperactivity, constant seek for gratification, motivational instability, cognitive impulsivity (works with hurry) and anxiety, has been the core symptoms in hyperactive sub-type (Rubia et al., 2009). Fronto-striatal circuits are highly replicated in literature for hyperactive children, pharmacological treatment with stimulants like Methylphenidate produces positives psychophysiological changes in cortical (cognitive) and fronto-striatal (dopaminereward systems) functioning (Zhu et al., 2011). It's been established that inhibitory control is the core mechanism for this variant (Barkley, 2009), this executive function permit optimal cognition and behavior regulation; metanalysis on 19 studies using Stroop interference measure (inhibitory control), indicates that this process is consistently compromised in ADHD (Lansbergen, Kenemans \& van Engeland, 2007).

During development dynamic interactions between brain regions changes, especially in fronto-estriatal circuits, as a result hyperactivity significantly diminishes during late childhood-adolescence; instead sensation seeking (for reward-goal oriented activities) develops in a $\cap$-shaped along childhood-adolescence-adulthood. Motivational cues for potential reward are specifically incremented in adolescence (striate hyper-responsiveness), and can lead to riskier choices during goal-oriented behavior (Somerville \& Casey 2010). Diverse studies that includes functional neuroimaging have found that only during adolescence a striate hyperactivation for reward expectation occurs (Van Leijenhorst et al., 2010), and although risk-detection capacity (in normal subjects) is adult-competent since 13 years old (Crone et al., 2005); in ADHD-adults is clinically diminished (Malloy-Diniz et al., 2007). 
Emotional dysregulation (e.g. high sensation seeking despite risk consequences) in ADHD could lead to greater risk for psychopathological comorbidity (Blaskey, Harris \& Nigg, 2008). Grall-Bronec et al. (2011) studied 85 adults with pathological gambling (this disorder is characterized by inadequate reward-regulation - Brevers et al., 2011-), finding that more than $25 \%$ of this sample presented history of ADHD, this subgroup presented elevated anxiety and impulsivity, more severe gambling problems, a higher frequency of psychiatric comorbidities and an elevated suicidal-risk.

\section{Impulsivity as a fronto-temporal-ADHD type}

Behavioral impulsivity, aggressiveness, conduct disorder, and emotional outburst; are the core symptoms in impulsivity variant (Harty et al., 2009). Fronto-temporal mechanisms are responsible for optimum regulation of emotional-based behavior (Gupta, Koscik, Bechara \& Tranel, 2011), adequate frontal regulation to emotional-based responses represent an important prerequisite for interpersonal and social interactions, allowing subjects to regulate verbal and behavioral interactions; these processes are fundamental for socially-adjusted behavioral and personality development during childhood (Damasio, 2005). Based on genetics studies low serotonin metabolism has been outlined as the key neurotransmitter system for behavioral-impulsivity and aggression in ADHD (Oades et al., 2008). By using magnetic resonance imaging Boes et al. (2008) studied the relationship between impulsive control and volume-size for diverse brain regions (including amygdala, anterior cingulate cortex and prefrontal cortex) in 61 normal-boys from 7 to 17 years old; finding that subjects with poorer impulsivity control presented (significantly different) less volume in the right ventro-medial -orbital- cortex.

Literature indicates that ADHD and conduct disorder combination represent a very important clinical condition (Waschbusch, 2002). Barkley and Fischer (2010) studied the influence of emotional impulsiveness over social, laboral and daily live activities, in 135 ADHD-young-adults; finding that if ADHD-symptoms are still persistent in adulthood, emotional impulsiveness severity contributes to significant impairment in occupational, educational, legal, and financial aspects. Authors highlight the importance of impulsivity in ADHD-criteria, considering it's at least as important as inattention/hyperactivity dimension for the development of adequate social, occupational and interpersonal functioning. Although highly important, impulsivity dimension is under-represented in DSM-IV criteria for ADHD (Barkley, 2009).

\section{Comorbidity classification by neuropsychological criteria}

In most cases in literature comorbidity is reported in relationship to prevalence (clinicalepidemiological approach), however ADHD-subtypes in adults are associated with different clinical comorbid correlates (Sprafkin et al., 2007), results coincide in describing predominant behavioral-psychological disorders in combined-ADHD, and predominant cognitive disorders at inattentive type (Murphy, Barkley \& Bush, 2002). To explore comorbid profiles from a neuropsychological point of view, a sample of 61 male-children with ADHD-diagnosis (DSM-IV criteria) were selected. Participants had between 6 and 10 years-old (mean: 7.6). Inclusion criteria were: not-medicated for ADHD (or any other neurodevelopemental/psychiatric disorder), no history of psychological treatment, normal I.Q. (WISC); exclusion criteria: others non-related neurodevelopmental disorder (epilepsy, 
cognitive deficit, etc). All subjects were evaluated with diverse neuropsychological tests, and evaluated by clinical-psychological criteria (see Flores Lázaro, 2009 for details). On the first analysis 20 subjects with ADHD-attentive type (ADD) (group one) were compared vs. 10 subjects with ADHD-combined (ADHD-C) type and 10 subjects with ADHD-impulsivity with or without hyperactivity-variant (ADHD-I-H) (group two: ADHD-C-I).

Based on Diamond (2005) proposal, comorbidity was divided in behavioral-psychological, and cognitive. Statistical analysis was performed by Fisher's exact test (FET). All results including tables are adapted from Flores Lázaro (2009)*

Data presented in tables 1 and 2, supports Barkley's and Diamond's basic division, illustrating that both groups are significantly different in behavioral-psychological and cognitive dimensions. These results coincide with other studies (Capdevila-Brophy, et al., 2005; Maedgen \& Carlson, 2000). ADHD-C-I group is mainly characterized by behavioralpsychological comorbidity; whereas cognitive comorbidity represents the main characteristic for ADD group.

\begin{tabular}{|l|c|c|c|}
\hline \multicolumn{1}{|c|}{ Behavioral-psychological comorbidity } & ADHD-C-I & ADD & FET \\
\hline Mood disorders & $43 \%$ & $10 \%$ & .017 \\
\hline Conduct disorder an/or agressivity & $39 \%$ & $8 \%$ & .040 \\
\hline Negativistic defiant disorder & $39 \%$ & $0 \%$ & .032 \\
\hline Anxiety/anxiety disorder & $35 \%$ & $8 \%$ & .040 \\
\hline Socialization difficulties & $35 \%$ & $40 \%$ & .432 \\
\hline Avoiding to follow rules-instructions & $39 \%$ & $0 \%$ & .001 \\
\hline Infantilization & $39 \%$ & $0 \%$ & .002 \\
\hline Low tolerance to frustration & $35 \%$ & $17 \%$ & .101 \\
\hline Insecurity (low self-concept) & $13 \%$ & $36 \%$ & .022 \\
\hline
\end{tabular}

Table 1. Percentage on behavioral-psychological comorbidity and differences between ADHD-C-I and ADD

\begin{tabular}{|l|c|c|c|}
\hline \multicolumn{1}{|c|}{ Cognitive comorbidity } & ADHD-C-I & ADD & FET \\
\hline Visoespatial difficulties & $39 \%$ & $70 \%$ & .014 \\
\hline Mathematics learning disorder & $17 \%$ & $40 \%$ & .032 \\
\hline Reading learning disorder & $26 \%$ & $35 \%$ & .356 \\
\hline General learning disorder & $4 \%$ & $35 \%$ & .001 \\
\hline Language difficulties/dysphasia & $4 \%$ & $30 \%$ & .012 \\
\hline
\end{tabular}

Table 2. Percentage on cognitive comorbidity and differences between ADHD-C-I and ADD

It's important to outlined that socialization difficulties are due to different causes in each group (evitative vs disruptive), reading learning disorder are also due to different neuropsychological causes (Roselli, Matute \& Ardila, 2006). Even when general-clinical-

* Partially/totally reproduced from "Características de comorbilidad en los diferentes subtipos de trastorno por déficit de atención con hiperactividad" de J.L. Flores Lázaro, 2009, Psicothema, 21(4), p. $594,595$. Copyright 2009 del Colegio Oficial de Psicólogos del Principado de Asturias. Reproducido con permiso" 
criteria coincide, psychological and neuropsychological analysis permits to scientifically differentiate specific differential-causes for the same criteria. Literature has progressively demonstrated that clinical-empirical dimensions without psychological, psychophysiological, or neuropsychological scientifically bases should not serve as professional taxonomic criteria (McGough \& McCracken, 2005; Stefanatos \& Baron, 2007).

\section{Hyperactive, inattentive and impulsive variants analysis}

During transition from childhood to adolescence, emotional regulation represents a central component for ADHD-mental health (Barkley \& Fisher, 2010), due that impulsivity variant is underrecognized in DSM-IV criteria (Barkley, 2009), and that emotional dysregulation is a core characteristic for impulsivity subtype (Harty et al., 2009); ADHD-Impulsivity variant still represents a very important clinical subgroup for scientific study.

Current knowledge on cognitive neuroscience and neuropsychology permits to validate the pertinence to investigate differences among hyperactive vs. impulsive subjects. Therefore a second analysis was performed with a three-group division: 20 children with inattentive variant (ADD), 20 children with combined variant (ADHD-C), and 21 children with impulsivity variant -with or without hyperactivity- (ADHD-I). Results are presented in tables 3 and 4, data shows a clear cognitive to behavioral-psychological comorbidity transition: inattentive-hyperactive-impulsive. As expected by neuropsychological criteria, impulsivity variant presents the highest significant-frequent behavioral-psychological comorbidity; Inattentive variant continues to present the highest significant-frequent cognitive comorbidity. Interestingly Hyperactive variant lies in the middle range on this group-division. Results illustrate Barkley's point of view that impulsivity-variant represents a sufficiently differentiated clinical-group.

Impulsivity-variant suggests fronto-temporal mechanisms as the main causes for comorbidity, differently to fronto-strital mechanism on hyperactive-variant. However specifics neuropsychological, psychophysiological, structural and functional neuroimaging studies should differentiate fronto-parietal, fronto-striatal and fronto-temporal mechanisms for each cases.

\begin{tabular}{|l|c|c|c|c|c|}
\hline \multicolumn{1}{|c|}{ Behavioral-psychological comorbidity } & ADHD-I & FET & ADHD-C & FET & $A D D$ \\
\hline Mood disorders & $47 \%$ & .202 & $31 \%$ & .118 & $10 \%$ \\
\hline Conduct disorder an/or agressivity & $42 \%$ & .191 & $26 \%$ & .204 & $10 \%$ \\
\hline Negativistic defiant disorder & $31 \%$ & .002 & $0 \%$ & & $0 \%$ \\
\hline Anxiety/anxiety disorder & $37 \%$ & .415 & $31 \%$ & .118 & $10 \%$ \\
\hline Socialization difficulties & $45 \%$ & .191 & $26 \%$ & .250 & $40 \%$ \\
\hline Avoiding to follow rules-instructions & $52 \%$ & .038 & $25 \%$ & .024 & $0 \%$ \\
\hline Infantilization & $26 \%$ & .329 & $42 \%$ & .002 & $0 \%$ \\
\hline Low tolerance to frustration & $31 \%$ & .585 & $35 \%$ & .137 & $15 \%$ \\
\hline Insecurity (low self-concept) & $5 \%$ & .284 & $15 \%$ & .137 & $36 \%$ \\
\hline
\end{tabular}

Table 3. Percentage on behavioral-psychological comorbidity and differences between groups 


\begin{tabular}{|l|c|c|c|c|c|}
\hline \multicolumn{1}{|c|}{ Cognitive comorbidity } & ADHD-I & FET & ADHD-C & FET & ADD \\
\hline Visoespatial difficulties & $70 \%$ & .100 & $42 \%$ & .222 & $26 \%$ \\
\hline Mathematics learning disorder & $40 \%$ & .250 & $25 \%$ & .081 & $5 \%$ \\
\hline Reading learning disorder & $34 \%$ & .500 & $40 \%$ & .065 & $15 \%$ \\
\hline General learning disorder & $34 \%$ & .022 & $5 \%$ & .488 & $0 \%$ \\
\hline Language difficulties/dysphasia & $30 \%$ & .118 & $10 \%$ & .232 & $0 \%$ \\
\hline
\end{tabular}

Table 4. Percentage of cognitive comorbidity and differences between groups

\section{Comorbid profiles according to ADHD-variants}

Comorbid characteristics among different ADHD-subtypes analyzed are specific, behavioral-psychological comorbidity is listed from more to less frequent:

- Inattentive profile: socialization (evitative -type), and low self-concept.

- Hyperactive profile: infantilization, low-tolerance to frustration, anxiety/anxiety disorder, mood disorders, conduct disorder/aggressiveness, socialization, and avoiding to follow rules and instructions,

- Impulsivity variant: following rules, limits and instructions. Mood disorders, socialization (disruptive-type), conduct disorder/aggressiveness, anxiety/anxiety disorder, negativistic defiant disorder, low-tolerance to frustration, and infantilization.

Cognitive comorbidity is listed from more to less frequent:

- Inattentive: visoespatial, mathematics, reading, and general learning difficulties, language/dysphasia.

- Hyperactive: visoespatial, reading, and mathematics learning difficulties.

- Impulsive: visoespatial, reading learning disorder.

\begin{tabular}{|l|c|}
\hline \multicolumn{1}{|c|}{ Behavioral-psychological comorbidity } & FET \\
\hline Mood disorders & .012 \\
\hline Conduct disorder an/or agressivity & .025 \\
\hline Negativistic defiant disorder & .003 \\
\hline Anxiety/anxiety disorder & .048 \\
\hline Socialization difficulties & .607 \\
\hline Avoiding to follow rules-instructions & .000 \\
\hline Infantilization & .014 \\
\hline Low tolerance to frustration & .181 \\
\hline Insecurity (low self-concept) & .015 \\
\hline
\end{tabular}

Table 5. Differences on behavioral-psychological comorbidity between extreme groups: ADD vs ADHD-I-H

\section{Extreme groups division}

As shown in tables 3 and 4, ADD and ADHD-I groups represent extreme comorbidity: behavioral-psychological vs cognitive. In order to analyze statistical differences among these groups FET has been applied. Results are presented in table 5 and 6, data indicate 
clearer/most frequent significant differences both comorbidity-types; inclusion of children with Hyperactive-variant (a transitional group) tends to diminish statistical differences (see tables 3 and 4).

\begin{tabular}{|l|c|}
\hline \multicolumn{1}{|c|}{ Cognitive comorbidity } & FET \\
\hline Visoespatial difficulties & .005 \\
\hline Mathematics learning disorder & .006 \\
\hline Reading learning disorder & .100 \\
\hline General learning disorder & .003 \\
\hline Language difficulties/dysphasia & .007 \\
\hline
\end{tabular}

Table 6. Differences on cognitive comorbidity between extreme groups: ADD vs ADHD-I

\section{Conclusions}

Neuropsychology permit to establish a conceptual bridge between clinical and basics sciences (psychology and neurosciences). Applied neuropsychological research posses high environmental validity in clinical settings (Beblo et al., 2011). Several researchers have criticized the reluctance of psychiatry-practice to move toward scientifically oriented pathophysiology -neurosciences- more common in actual days to general medicine and psychology (McGough \& McCracken, 2005); from a neuropsychological point of view ADHD is mainly a disexecutive disorder in which several cognitive, behavioral and psychological consequences are present, in different form, at diverse ontogenetic moments. In ADHD, attention is only one of these consequences; and for an important number of cases is not the most important. Diverse clinicians and researches in this field began to underline the need for systematic neuropsychological evaluation in order to objectify attention disorders (Chambry et al., 2011), interpretations on these results should be made within valid scientific models (Drake \& Wallach, 2007; Stefanatos \& Baron, 2007). Professionals should understand basic neuropsychological and psychological mechanism causing ADHD: attention is ONLY one of the cognitive processes involved, due to inadequate development in executive function control; in most cases comorbidity is ALSO explained by the same psychophysiological and/or neuropsychological mechanisms; based on this comprehension intervention programs will be more specific, and above all: more scientifically oriented.

Drake and Wallach's fundamental question for psychology may be better answered in this form: ADHD-comorbidity is -mainly- a neuropsychological science.

\section{References}

American Psychiatric Association (2001). Manual diagnóstico y estadístico de los trastornos mentales-IV-TR. Barcelona: Masson.

Barkley, R.A., Brown, T.E. (2008). Unrecognized attention-deficit/hyperactivity disorder in adults presenting with other psychiatric disorders. CNS Spectrums., 13,,977-84.

Barkley, R.A. (1997). Behavioral inhibition, sustained attention and executive functions: Constructing a unifying theory of ADHD. Psychologycal Bulletin, 121, 65-94. 
Barkley, R.A. (2009). Advances in the diagnosis and subtyping of attention deficit hyperactivity disorder: what may lie ahead for DSM-V. Revista de Neurología. 27,48, S101-6.

Barkley, R.A. (2010). Against the status quo: revising the diagnostic criteria for ADHD. J Am Acad Child Adolesc Psychiatry. 49,3,205-7.

Barkley R.A. \& Fischer, M. (2010). The unique contribution of emotional impulsiveness to impairment in major life activities in hyperactive children as adults. Journal of the American Academy of Child and Adolescent Psychiatry. 49,5,503-13.

Beblo, T., Sinnamon, G. \& Baune, B.T. (2011). Specifying the Neuropsychology of Affective Disorders: Clinical, Demographic and Neurobiological Factors. Neuropsychology Review. (Epub ahead of print). DOI: 10.1007/s11065-011-9171-0

Blaskey, L.G., Harris, L.J. \& Nigg, J.T. (2008). Are sensation seeking and emotion processing related to or distinct from cognitive control in children with ADHD?, Child Neuropsychology, 14,4,353-71.

Boes, A.D., Tranel, D., Anderson, S.W., Nopoulos, P. (2008). Right anterior cingulate: a neuroanatomical correlate of aggression and defiance in boys. Behavioral Neurosciences, 122,3.677-84.

Brevers, D., Cleeremans, A., Bechara, A., Laloyaux, C., Kornreich, C., Verbanck, P., Noël, X. (2011). Time course of attentional bias for gambling information in problem gambling. Psychology of Addictive Behaviors. doi: 10.1037/a0024201

Castel, A.D., Lee, S.S., Humphreys, K.L. \& Moore, A.N. (2001). Memory capacity, selective control, and value-directed remembering in children with and without attentiondeficit/hyperactivity disorder (ADHD). Neuropsychology. 25,1,5-24.

Chambry, J., Billard, C., Guinard, M., Lacaze, E., Idiart, M.E., Delteil-Pinton, F. Cohen de Lara, A. (2011). [Attention deficit disorder: Multidisciplinary observational study over 1 year. Encephale, 373, 180-190.

Capdevila-Brophy, C., Artigas-Pallares, J., Ramírez-Mallafré, A., López-Rosendo, M., Real, J., \& Obiols-Landrich, J.E. (2005). Fenotipos neuropsicológicos del trastorno por déficit atencional/hiperactividad, ¿existen diferencias entre los subtipos? Revista de Neurología, 40, 17-23.

Chambry, J., Billard, C., Guinard, M., Lacaze, E., Idiart, M.E., Delteil-Pinton, F. \& Cohen de Lara, A. (2011). Attention deficit disorder: Multidisciplinary observational study over 1 year. Encephale, 37, 3,180-190.

Crone, E.A., Bunge, S.A., Latenstein, H., van der Molen, M.W.(2005). Characterization of children's decision making: sensitivity to punishment frequency, not task complexity. Child Neuropsychology, 11,3,245-63.

Damasio, A. (2005). Human behavior: brain trust. Nature, 2,435,571-2.

Diamond, A. (2005). Attention deficit disorder (attention deficithyperactivity disorder without hyperactivity): A neurobiologycally and behaviorally distinct disorder Attention deficit-hyperactivity disorder (with hyperactivity). Developmental psychopathology, 17, 803-825.

Diamond, A. \& Amso, D. (2008). Contributions of Neuroscience to Our Understanding of Cognitive Development. Current Directions in Psychological Sciences, 17,2,136-141.

Diamond A. (2011). Biological and social influences on cognitive control processes dependent on prefrontal cortex. Progress in Brain Research, 189,319-39. 
Donohew, R.L., Hoyle, R.H., Clayton, R.R., Skinner, W.F., Colon, S.E. \& Rice, R.E. (1999). Sensation seeking and drug use by adolescents and their friends: Models for marijuana and alcohol. Journal of Studies on Alcohol, 60, 622-631.

Drake, R.E., y Wallach, M.A. (2007). Is comorbidity a Psychological Science? Clinical Psychology: Science and Practice, 14, 20-22.

Fair, D.A., Dosenbach, N.U., Church, J.A., Cohen, A.L., Brahmbhatt, S., Miezin, F.M., et al. (2007). Development of distinct control networks through segregation and integration. Proceedinga of the National Academy of Sciences U S A. 14,104,1350712.

Flores Lázaro J.C. (2009). [Comorbidity characteristics in the different subtypes of attention deficit-hyperactivity disorder. Psicothema, 21,4, 592-7.

Flory, K., Milich, R., Lynam, D.R., Leukefeld, C., y Clayton, R. (2003). Relation between childhood disruptive behavior disorders and substance use and dependence symptoms in young adulthood: Individuals with symptoms of attentiondeficit/hyperactivity disorder and conduct disorder are uniquely at risk. Psychology of Addictive Behaviors, 17, 151-158

Freitag, C.M., Hänig, S., Schneider, A., Seitz, C., Palmason, H., Retz, W. \& Meyer, J. (2011). Biological and psychosocial environmental risk factors influence symptom severity and psychiatric comorbidity in children with ADHD. Journal of Neural Transmission. 2011 May 31. [Epub ahead of print]

Gamo, N.J., Phil, M., Wang, M., \& Arnsten, A. (2010). Methylphenidate and Atomoxetine Enhance Prefrontal Function Through a2-Adrenergic and Dopamine D1 Receptors. Journal of the American Academy of Child and Adolescence Psychiatry, 49,10, 1011-1023.

Grall-Bronnec, M., Wainstein, L., Augy, J., Bouju, G., Feuillet, F., Vénisse, J.L. \& SébilleRivain, V. (2011). Attention Deficit Hyperactivity Disorder among Pathological and At-Risk Gamblers Seeking Treatment: A Hidden Disorder. European Addiction Research, 7,17,231-240.

Gupta, R., Koscik, T.R., Bechara, A., Tranel, D. (2011). The amygdala and decision-making. Neuropsychologia, 49,4,760-6.

Hale, T.S., Smalley, S.L., Walshaw, P.D., Hanada, G., Macion, J., McCracken, J.T., McGough, J.J., Loo, S.K. (2010). Atypical EEG beta asymmetry in adults with ADHD. Neuropsychologia, 48,12,3532-9.

Harty, S.C., Miller, C.J., Newcorn, J.H, \& Halperin JM. (2009). Adolescents with childhood ADHD and comorbid disruptive behavior disorders: aggression, anger, and hostility. Child Psychiatry and Human Development, 40,1,85-97.

Kessler, R.D, Adler,L., Barkley, R. Biederman, J. Conners, K., Demler, O. et al. 2006). The Prevalence and Correlates of Adult ADHD in the United States: Results From the National Comorbidity Survey Replication. American Journal of Psychiatry, 163, 716723).

Klassen, A.F., Miller, A., \& Fine, S. (2004). Health-related quality of life in children and adolescents who have a diagnosis of attention-deficit/hyperactivity disorder. Pediatrics, 114, 541-547.

Lahey, B.B. \& Willcutt, E.G. (2010). Predictive validity of a continuous alternative to nominal subtypes of attention-deficit/hyperactivity disorder for DSM-V. Journal of Clinical Child and Adolescent Psychology, 39,6,761-75. 
Lansbergen, M.M., Kenemans, J.L. \& van Engeland, H. (2007). Stroop interference and attention-deficit/hyperactivity disorder: a review and meta-analysis. Neuropsychology, 21,2,251-62.

Maedgen, J.W. \& Carlson, C.L. (2000). Social functioning and emotional regulation in the attention deficit hyperactivity disorder subtypes. Journal of Clinical Child Psychology, $29,30-42$.

Malloy-Diniz, L., Fuentes, D., Leite, W.B., Correa, H. \& Bechara, A. (2007). Impulsive behavior in adults with attention deficit/ hyperactivity disorder: characterization of attentional, motor and cognitive impulsiveness. Journal of the International Neuropsychological Society, 13,4,693-8.

McGough, J.J., Smalley, S.L., McCracken, J.T., Yang, M., Del’Homme, M., Lynn, D.E. \& Loo, S. (2005). Psychiatric Comorbidity in Adult Attention Deficit Hyperactivity Disorder: Findings From Multiplex Families. American Journal of Psychiatry, 162, 1621-1627.

McGough, J.J. \& McCracken, J.T. (2006). Adult Attention Deficit Hyperactivity Disorder: Moving Beyond DSM-IV. American Journal of Psychiatry, 163, 1673-1675.

McManis, M.H., Kagan, J., Snidman, N.C., Woodward, S.A. (2002). EEG asymmetry, power, and temperament in children. Developmental Psychobiology, 41,2, 169-77.

Manassis, K., Tannock, R., Young, A. \& Francis-John, S., Cognition in anxious children with attention deficit hyperactivity disorder: a comparison with clinical and normal children. Behavioral and Brain Functions, 3,4, 1-10.

Murphy, K.R., Barkley, R.A. \& Bush, T. (2002). Young adults with attention deficit hyperactivity disorder: subtype differences in comorbidity, educational, and clinical history. Journal of Nervous and Mental Disorders, 190,3,147-57.

Oades, R.D., Lasky-Su, J., Christiansen, H., Faraone, S.V., Sonuga-Barke, E.J., Banaschewski, T., Chen, W., et al. ( 2008). The influence of serotonin- and other genes on impulsive behavioral aggression and cognitive impulsivity in children with attentiondeficit/hyperactivity disorder (ADHD): Findings from a family-based association test (FBAT) analysis. Behavioral and Brain Functions, 20,4-48.

O'Brien, J.W., Dowell, L.R., Mostofsky, S.H., Denckla, M.B., Mahone, E.M (2010). Neuropsychological profile of executive function in girls with attentiondeficit/hyperactivity disorder. Archives of Clinical Neuropsychology; 25,7,656-70.

Pliszka, S.R. (2006). Subtyping ADHD based on comorbidity. The ADHD Report, 14,1-5.

Rosselli, M., Matute, E., y Ardila, A. (2006). Predictores neuropsicológicos de la lectura en español. Revista de Neurología, 42, 202-210.

Rhee, S.H., Willcutt, E.G., Hartman, C.A., Pennington, B.F., \& Defries, J.C. (2007). Test of alternative hypotheses explaining the comorbidity between attentiondeficit/hyperactivity disorder and conduct disorder. Journal of Abnormal Child Psychology, 35, 536-542.

Romine, C.B., Reynolds. C.R. (2005). A model of the development of frontal lobe functioning: findings from a meta-analysis. Applied neuropsychology, 12,4,190-201.

Rubia, K., Halari, R., Cubillo, A., Mohammad, A.M., Scott, S., Brammer, M.(2010). Disorderspecific inferior prefrontal hypofunction in boys with pure attentiondeficit/hyperactivity disorder compared to boys with pure conduct disorder during cognitive flexibility. Human Brain Mapping, 31,12,1823-33. 
Rubia, K., Halari, R., Cubillo, A., Mohammad, A.M., Brammer, M., Taylor, E. (2009). Methylphenidate normalises activation and functional connectivity deficits in attention and motivation networks in medication-naïve children with ADHD during a rewarded continuous performance task. Neuropharmacology, 57,7-8,640-52.

Ruhl, U., Rentsch, A., Bernardi, C., Türke-Teubner, V., Becker, E., Kirch, W., Margraf, J. \& Hach, I. (2009). Associations Between Childhood ADHD and Other Mental Disorders in Young Women. German Journal of Psychiatry, 12, 8-13).

Schwartz, C.E., Kunwar, P.S., Greve, D.N., Moran, L.R., Viner, J.C., Covino, J.M., Kagan, J., Stewart, S.E., Snidman, N.C., Vangel, M.G. \& Wallace, S. (2010). Structural differences in adult orbital and ventromedial prefrontal cortex predicted by infant temperament at 4 months of age. Archives of General Psychiatry, 67, 1,78-84.

Shaw, P., Gilliam, M., Liverpool, M., Weddle, C., Malek, M., Sharp, W., et al. (2011). Cortical development in typically developing children with symptoms of hyperactivity and impulsivity: support for a dimensional view of attention deficit hyperactivity disorder. American Journal of Psychiatry, 168,2,143-51.

Shuai, 1.C., Chan, 1.C. \& Wang, Y. (2011). Executive Function Profile of Chinese Boys with Attention-Deficit Hyperactivity Disorder: Different Subtypes and Comorbidity. Archives of Clinical Neuropsychology, 26, 2, 120-132.

Simon, V. Czobor, P., Balint, S., Mesza, A. \& Bitter, I. (2009). Prevalence and correlates of adult attention-deficit hyperactivity disorder:meta-analysis. The British Journal of Psychiatry, 194, 204-211.

Stefanatos, G.A., \& Baron I.S. (2007). Attention-deficit/hyperactivity disorder: A neuropsychologycal perspective towards DSM-IV. Neuropsychology Review, 17, 5-38.

Somerville, L.H. \& Casey, B.J. (2010). Developmental neurobiology of cognitive control and motivational systems. Current Opinion in Neurobiology, 20, 2, 236-241.

Sprafkin, J., Gadow, K.D., Weiss, M.D., Schneider, J. \& Nolan, EE. (2007) Psychiatric comorbidity in ADHD symptom subtypes in clinic and community adults. Journal of Attention Disorders, 11,2, 114-24.

Stuss, D.T., y Levine, B (2000). Adult clinical neuropsychology, lessons from studies of the frontal lobes. Annual Review of Psychology, 53,401-403.

Taurines, R., Schmitt, J., Renner, T., Conner, A.C., Warnke, A. \& Romanos, M. (2010). Developmental comorbidity in attention-deficit/hyperactivity disorder. Attention Deficit Hyperactive Disorders; 2,4,267-89.

Waschbusch, D.A. (2002). A meta-analytic examination of comorbid hyperactive-impulsiveattention problems and conduct problems. Psychologycal Bulletin, 128, 118-50.

Van Leijenhorst, L. Moor, B.G. Op de Macks, Z.A., Rombouts, S., Westenberg, P.M. \& Crone, E.A. (2010). Adolescent risky decision-making: Neurocognitive development of reward and control regions. Neuroimage, 15;51,345-55.

Yang, L., Ji, N., Guan, L.L., Chen, Y., Qian, Q.J., y Wang Y.F. (2007). Co- morbidity of attention deficit hyperactivity disorder in different age group. Beijing $\mathrm{Da}$ Xue Xue Bao, 39, 229-232

Zhu, J., Spencer, T.J., Liu-Chen, L.Y., Biederman, J. \& Bhide, P.G. (2011). Methylphenidate and $\mu$ opioid receptor interactions: A pharmacological target for prevention of stimulant abuse. Neuropharmacology, 61,1-2, 283-92. 


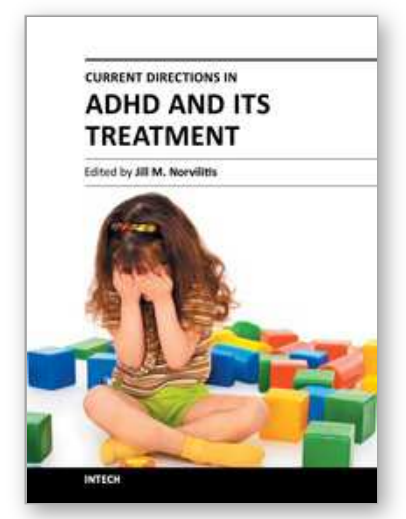

\author{
Current Directions in ADHD and Its Treatment \\ Edited by Dr. Jill M. Norvilitis
}

ISBN 978-953-307-868-7

Hard cover, 302 pages

Publisher InTech

Published online 15, February, 2012

Published in print edition February, 2012

The treatment of Attention Deficit Hyperactivity Disorder is a matter of ongoing research and debate, with considerable data supporting both psychopharmacological and behavioral approaches. Researchers continue to search for new interventions to be used in conjunction with or in place of the more traditional approaches. These interventions run the gamut from social skills training to cognitive behavioral interventions to meditation to neuropsychologically-based techniques. The goal of this volume is to explore the state-of-the-art in considerations in the treatment of ADHD around the world. This broad survey covers issues related to comorbidity that affect the treatment choices that are made, the effects of psychopharmacology, and nonmedication treatments, with a special section devoted to the controversial new treatment, neurofeedback. There is something in this volume for everyone interested in the treatment of ADHD, from students examining the topic for the first time to researchers and practitioners looking for inspiration for new research questions or potential interventions.

\title{
How to reference
}

In order to correctly reference this scholarly work, feel free to copy and paste the following:

Julio César Flores Lázaro and María Alejandra Salgado Soruco (2012). Comorbidity in ADHD: A Neuropsychological Perspective, Current Directions in ADHD and Its Treatment, Dr. Jill M. Norvilitis (Ed.), ISBN: 978-953-307-868-7, InTech, Available from: http://www.intechopen.com/books/current-directions-inadhd-and-its-treatment/comorbidity-in-adhd-a-neuropsychological-perspective

\section{INTECH}

open science | open minds

\section{InTech Europe}

University Campus STeP Ri

Slavka Krautzeka 83/A

51000 Rijeka, Croatia

Phone: +385 (51) 770447

Fax: +385 (51) 686166

www.intechopen.com

\section{InTech China}

Unit 405, Office Block, Hotel Equatorial Shanghai

No.65, Yan An Road (West), Shanghai, 200040, China

中国上海市延安西路65号上海国际贵都大饭店办公楼 405 单元

Phone: +86-21-62489820

Fax: $+86-21-62489821$ 
(C) 2012 The Author(s). Licensee IntechOpen. This is an open access article distributed under the terms of the Creative Commons Attribution 3.0 License, which permits unrestricted use, distribution, and reproduction in any medium, provided the original work is properly cited. 